\title{
O controle migratório nas fronteiras do Brasil durante a pandemia: sinais do autoritarismo à nossa porta
}

\author{
Migration control at the borders of Brazil during the pandemic: \\ signs of authoritarianism at our door
}

Control migratorio en las fronteras de Brasil durante la pandemia: señales de autoritarismo en nuestra puerta

Recebido em 30-03-2021

Modificado em 27-04-2021

Aceito para publicação em 14-05-2021

\section{doi) https://doi.org/10.47456/simbitica.v8i2.36377}

\author{
Elisa Marina Fonseca \\ ORCID: 0000-0002-3167-613X
}

Mestranda do Programa de Ciências Sociais Aplicadas da Universidade Estadual de Ponta Grossa/PR, bolsista da Coordenação de Aperfeiçoamento de Pessoal de Nível Superior (CAPES). Graduada em Direito e especialista em Direito e Processo Administrativo pela mesma Universidade. E-mail: elisafonseca.jus@gmail.com

\section{Mirna de Lima Medeiros}

ORCID: 0000-0002-7198-9835

Pós-Doutora em Administração de Organizações pela Faculdade de Economia, Administração e Contabilidade de Ribeirão Preto, da Universidade de São Paulo. Graduada em Turismo pela Universidade Federal de Minas Gerais. É Professora Adjunta da Universidade Estadual de Ponta Grossa.

E-mail: mirnadelimamedeiros@gmail.com

\section{João Irineu de Resende Miranda}

ORCID: 0000-0003-1838-6610

Doutor em Direito Internacional pela Universidade de São Paulo, graduado em Direito pela Universidade Estadual de Ponta Grossa. Professor do Curso de Direito e do Programa de Pós-Graduação em Ciências Sociais Aplicadas da Universidade Estadual de Ponta Grossa. E-mail: joaoirineu78@gmail.com

\section{Resumo}

$\mathrm{O}$ fechamento de fronteiras foi uma medida tomada pela maioria dos países no combate à pandemia de Covid-19, inclusive o Brasil, mediante portarias interministeriais do governo federal. A proposta desta pesquisa é analisar tais portarias, quais as motivações do Poder Executivo, e o que esses atos significam para a democracia e para os direitos migratórios. Pelo método histórico-dedutivo, utilizando-se de pesquisa bibliográfica, realizou-se uma revisão teórica sobre o governo burocrático e autoritário na perspectiva de Arendt. Por meio de pesquisa documental (portarias, Ação Civil Pública e reportagens), analisou-se a legalidade das portarias que determinaram as restrições migratórias. Concluiu-se que o fechamento de fronteiras, no Brasil, é um projeto político autoritário de contenção migratória, não do vírus: as portarias interministeriais sob análise representam a utilização da burocracia pelo poder político, para subverter o sistema legal.

Palavras-chave: migrações; pandemia; democracia; burocracia. 


\section{Introdução}

A mobilidade humana é um fenômeno geográfico e social que sofreu grandes impactos com o surgimento da Covid-19, classificada como pandemia pela Organização Mundial de Saúde (OMS) desde março de 2020. Essa classificação se dá pelo fato de que a doença causada pelo novo vírus (Sars-CoV-2) ultrapassou as fronteiras do país onde se originou, atingindo uma contaminação em nível global (Neto; Garcia; Spinussi, 2020), situação que perdura até o momento. Atualmente os deslocamentos são facilitados pela variedade de meios de transportes, conectando espaços geograficamente distantes em curtos períodos de tempo. Esses fluxos rápidos e facilitados, numa conjuntura pandêmica, "[...] possibilitaram que pessoas contaminadas, sintomáticas ou assintomáticas, chegassem em outros países e, assim, a epidemia transformou-se em pandemia em poucas semanas" (Neto; Garcia; Spinussi, 2020:s/n). Considerando essa situação, uma das primeiras medidas foi a tentativa de contenção do vírus por meio de fechamento de fronteiras, visto que a disseminação de doenças infecciosas está diretamente relacionada com a fluidez e capilaridade de circulação de pessoas em escala mundial.

O fechamento de fronteiras tem impactos sociais, econômicos e geográficos decorrentes da contenção da mobilidade de mercadorias, mão de obra, serviços e, especialmente, de migrações humanas. A fim de conter a propagação do vírus, os Estados passaram a restringir a imigração em seus territórios, baseando-se em critérios de nacionalidade, procedência, estabelecendo procedimentos sanitários, de testagem ou quarentena (Chaves, 2020). Não foi diferente no caso brasileiro, que já soma pelo menos 28 instrumentos normativos (Portarias dos Ministérios do Governo Federal).

Dessa forma, a pandemia já apresenta reflexos nos processos migratórios relacionados ao território brasileiro, em especial à região transfronteiriça com a Bolívia e Venezuela. A crise sanitária tem servido de argumento para a mudança na forma como o governo federal trata o acolhimento humanitário de imigrantes no Norte do país. É certo que as medidas de restrição são necessárias, mas o que se pôde verificar também foram disposições questionáveis em relação ao controle epidemiológico, que retomam pontos da polêmica portaria 666/2019 ${ }^{1}$, do Ministério da Justiça. Após anos de avanço na legislação migratória, o Brasil tem sinalizado uma ameaça de regressão no tema, especialmente no discurso político.

\footnotetext{
${ }^{1}$ Conforme se verá adiante, tal Portaria foi um dos atos do Ministério da Justiça considerado por diversas instituições como um retrocesso legal, contrariando o sistema normativo brasileiro, além de ter disposições contra legem.
} 
Para além de um tema que se limite às migrações, o controle de fronteiras, como tem sido executado, denota um caráter autoritário de retomada de disposições da legislação do regime militar. O Poder Executivo, como se verá, tem contrariado disposições constitucionais e legais sobre migrações mediante portarias, o que é um risco para a efetividade dos direitos humanos e para a própria democracia. Dessa forma, a proposta deste trabalho foi realizar uma análise do fechamento de fronteiras determinado pelas portarias interministeriais do governo federal, as motivações do executivo e o que esses atos significam em uma democracia.

Para tanto, optamos pelo método histórico-dedutivo, utilizando-se de pesquisa bibliográfica e documental. A pesquisa bibliográfica, que é preponderante no primeiro tópico, centrou-se nos temas do governo por meio da burocracia e aumento do discurso nacionalista, e pautou-se principalmente em Hannah Arendt. A escolha por esse norte teórico deu-se pelo fato de a autora (uma apátrida judia que se refugiou nos Estados Unidos após perder a nacionalidade alemã) ser a cientista política responsável por profundas análises conjunturais políticas sobre a ascensão e declínio da Alemanha nazista. Em "Origens do Totalitarismo", rastreou os elementos dos governos totalitários que alcançaram o auge durante a Segunda Guerra Mundial.

A etapa documental contemplou o arcabouço legal (análise da legislação migratória e das portarias ministeriais decretadas desde o início da pandemia, em março de 2020, até a finalização da pesquisa, em março de 2021), a fundamentação de ações opostas às portarias, bem como a cobertura midiática. Assim, no segundo tópico, analisou-se como o ordenamento jurídico brasileiro classifica os atos normativos do Poder Executivo hierarquicamente, e porque existe ilegalidade formal nas portarias ministeriais que versam sobre o tema migratório.

No terceiro tópico, elencaram-se as portarias existentes e localizaram-se as disposições que seriam contra legem (ilegalidade material, além da formal), apontando quais dispositivos constitucionais e legais elas violariam. Verificou-se ainda, por meio de análise de Ação Civil Pública (ACP) proposta pela Defensoria Pública da União (DPU) e Ministério Público Federal (MPF), e por meio de reportagens jornalísticas sobre as regiões Norte e Centro-Oeste, qual tem sido o contexto fático enfrentado pelos imigrantes que buscam ingressar em território brasileiro. A partir dessa contextualização, ponderou-se sobre em que medida as atividades de controle migratório têm sido regidas por lei em sentido formal ou por disposições administrativas (de menor legitimidade democrática), e qual tem sido o posicionamento das demais instituições que têm por dever constitucional a defesa do Estado Democrático de Direito. 
Por fim, subsumiu-se os aspectos fáticos aos teóricos, apontando posicionamentos sobre o futuro das migrações no mundo pós-pandêmico sob a perspectiva do crescimento do discurso nacionalista e protecionista encabeçado pela extrema-direita.

\section{Governo burocrático no século XX: como nasce o totalitarismo}

Conforme se analisará adiante, o governo federal brasileiro tem editado portarias e legislado por conta própria (contrariando o próprio ordenamento jurídico brasileiro) nas questões referentes à migração. A contrariedade ao sistema legal é evidente; ainda assim, as portarias continuam sendo executadas. Agindo dessa forma, a atual gestão federal tem se revelado um governo burocrático. Historicamente, governar por meio da burocracia (ao lado de outros elementos) foi uma característica dos governos despóticos.

Os pilares do totalitarismo do século XX, segundo Arendt (1989), foram o racismo, o imperialismo e o nacionalismo, a crise dos Estados nacionais, e a burocracia, que se cristalizaram e geraram o fenômeno totalitário na Europa. O totalitarismo é herdeiro do imperialismo, que por sua vez é resultado da assunção da burguesia à gestão estatal na Europa, cujos racismo, expansionismo e burocracia tiveram forte influência nos movimentos totalitários do pós-guerra (Arendt, 1989). Nesta análise, nos concentraremos na burocracia, ou melhor, no governo burocrático como ameaça à democracia, e de que forma isso tem sinalizado um perigo ao caso brasileiro, e ainda na retomada do discurso nacionalista.

Em Arendt, governar pela burocracia é ignorar a lei e governar por decretos, “[...] o que significa que a força, que no governo constitucional apenas faz cumprir a lei, se torna a fonte direta de toda legislação" (1989:275). Salientamos que o conceito de burocracia não se confunde com o conceito de governar por meio dela. Burocracia é "o necessário processo de racionalização e profissionalização de todas as organizações no mundo contemporâneo, uma vez que estas teriam de ter melhor desempenho para atingir seus fins diante da secularização e da maior competição interorganizacional" (Abrucio; Loureiro, 2018:24). Contudo ela não deve se confundir com a política: Wilson já escrevia sobre essa necessária separação; Weber previu os riscos da união (Abrucio; Loureiro, 2018).

Na burocracia ocorre um predomínio da técnica, da lógica, dos valores da segurança e da ordem pela qual tudo é regulado, em detrimento das condutas criativas e de risco que permeiam o mundo da política. Essa racionalidade extrema, que leva a uma prisão da modernidade, faz parte do poder burocrático, e coloca em risco os direitos individuais. Em análise ao governo burocrata que se instalava na Alemanha, Weber constatou que uma 
ditadura da burocracia estava a caminho, pois era um ambiente político em que os "ministros do governo eram originários dos quadros da alta burocracia civil e militar que se responsabilizavam perante o Kaiser mais do que ao Parlamento" (Abrucio; Loureiro, 2018:32). Afinal, demonstravam menos submissão à casa das leis do que ao executivo.

Um burocrata acredita que a lei é pouco prática e dá pouca liberdade ao legislador, pois é limitado por princípios, e aqueles que executam as leis são limitados pela necessidade de interpretar tais princípios. Apesar de todos os governos usarem decretos em emergências, num governo burocrático, tais instrumentos surgem como se fossem encarnações do próprio poder: "Não existem princípios gerais por trás do decreto que a simples razão possa entender, mas apenas circunstâncias que mudam constantemente e só um perito pode conhecer em detalhe" (Arendt, 1989:276). Isso porque é um governo de especialistas, uma minoria experiente, que governa sobre a maioria inexperiente.

Para um governo que assume a política de opressão, o governo pela burocracia é mais eficiente, já que um decreto ignora os estágios legais, e impele o raciocínio político da população. Em oposição ao governo das boas leis, que é o governo da sabedoria, o governo por decretos é governo da esperteza (Arendt, 1989).

Em que pese a burocracia primar pelo domínio da técnica e dos profissionais especializados em determinadas áreas, o atual governo brasileiro sequer promove a boa técnica de um governo de especialistas. O que se tem percebido pelos atos governamentais é que existe um procedimentalismo burocrático buscando governar por decretos e portarias em detrimento do processo legislativo democrático, e impondo aos órgãos vinculados a execução de tais determinações que contrariam os preceitos do Estado Democrático de Direito. Pari passu, o governo ataca publicamente o conhecimento, a ciência e a noção de especialização, além de uma ostensiva militarização de ministérios.

Conforme Hallal (2021), desde o início da atual gestão, a ciência sofre ataques por meio de cortes de verbas e de discurso negacionista. A citar exemplos, relembra a demissão de Ricardo Galvão, diretor do Instituto Nacional de Pesquisas Espaciais (INPE), que divulgou dados sobre o desmatamento no Brasil. Da mesma forma, Luiz Henrique Mandetta e Nelson Teich, que ocuparam o cargo de Ministro da Saúde, foram exonerados após defenderem recomendações científicas para o combate à pandemia de Covid-19. No campo da educação, o ex-ministro Weintraub não só menosprezou, mas minou a área educativa, que enfrentou corte de verbas e de bolsas de pesquisadores, problemas com o Fundo de Manutenção e Desenvolvimento da Educação Básica (Fundeb), entre outros. A Educação foi afetada pelo 
obscurantismo e pelas questões ideológicas da atual gestão, conforme atestam os verdadeiros especialistas da educação brasileira (Diniz, 2020).

Weber, o sociólogo que analisou os aspectos da burocracia na virada do século XIX ao $\mathrm{XX}$, atenta que a governabilidade que é submissa à burocracia é problemática, pois é rígida na aplicação das regras. A democracia é inimiga do domínio da burocracia, apesar de aquela acabar por fomentar a burocratização (Weber, 1999) ${ }^{2}$. O aparato burocrático desconsidera as múltiplas formas de relações humanas, o diálogo plural, as divergências, pondo em risco as normas que regem a democracia, pois tem uma autoridade racional-legal. É um aparato que demanda a homogeneidade social (Machado; Junior, 2018).

Em sua análise sobre o julgamento tardio de Adolf Eichmann, Arendt verifica o modo de pensar de um burocrata, e demonstra os riscos do governo burocrático. O nazista Eichmann foi responsável pelo envio de milhares de judeus aos campos de extermínio; nessa função, assumiu o papel técnico e mecânico de burocrata, separando-se de sua humanidade, ética, emoções, convicções. Alegou, em sua defesa, que apenas cumpriu ordens, respeitou a lei, e que, se não o fizesse, simplesmente outro faria em seu lugar. Não havia um ódio monstruoso em Eichmann, tampouco sombra de arrependimento sobre suas ações (Arendt, 1999). Deixou de manifestar sua dignidade humana e autonomia em nome de um projeto executado pela burocracia de uma máquina de guerra (Machado; Junior, 2018). Essa relação estabelecida por Arendt é tão forte que ela sugere a expressão "massacre administrativo" em substituição a genocídio, um instrumento de dominação imperialista que não era novidade (Arendt, 1999:255).

A burocracia, que estava especialmente presente no modo de agir do governo nazista, retira do ser humano a reflexividade crítica de seus atos, levando à "banalidade do mal" que acometeu aquela sociedade. Essa expressão criada pela autora refere-se a uma incapacidade de julgamento e de submissão total à lei: em um momento, o agente burocrata assina a compra de mantimentos e, com a mesma naturalidade, assina a deportação de pessoas, enviando-as para campos de extermínio. Tudo em nome do cumprimento da lei e do dever:

[...] o mal que atingiu proporções extremas na Alemanha nazi não foi um produto engenhoso de um único homem mal ou de mais de um; foi, sim, o resultado de ações de sujeitos burocratizados, despojados de reflexividade crítica pela nuvem ideológica perverso-burocrática de uma "Sagrada Alemanha" - ou seja, aos poucos cada um se transformou num dente de uma imensa engrenagem, num fiel seguidor

\footnotetext{
${ }^{2}$ E sempre cabe ter presente o fato - que várias vezes já encontramos e ainda voltaremos a examinar - de que a "democracia", como tal, apesar de fomentar inevitavelmente, mas sem querer, a burocratização, e também por causa disso, é inimiga do "domínio" da burocracia, podendo criar, neste papel, rupturas e obstáculos muito sensíveis para a organização burocrática (Weber, 1999:224).
} 
da lei, incapaz de empregar sobre a lei a força corrosiva do pensar (Machado; Junior, 2018:320).

O burocrata encarnado deixou de tratar com judeus, com pessoas, e passou a lidar com objetos, a serem calculados e analisados de acordo com as regras burocráticas: "se essa coisa/caso atende às regras e leis da burocracia, então ela serve; se não atende, então ela deve ser negligenciada, mesmo que seja digna de ser servida a partir de um ponto de vista humano" (Machado; Junior, 2018:324).

Eichmann, o nazista burocrata, não refletia criticamente sobre seus atos, era um ser desprovido da capacidade de pensar, um ser superficial que obedecia às ordens. Agia com cego obedecer a leis, com total irreflexão (Arendt, 1999). Nisso manifesta-se a dominação burocrática explicada por Weber. É uma relação de dominação inquebrável, na qual o indivíduo não consegue se desprender do aparato: "Claro que é importante para as ciências políticas e sociais que a essência do governo totalitário, e talvez a natureza de toda burocracia, seja transformar homens em funcionários e meras engrenagens, assim os desumanizando" (Arendt, 1999:256).

Apesar de apresentar uma visão pessimista da evolução da burocracia, Weber buscou formular soluções para conter o poder burocrático, que emergia como algo potencialmente despótico. A primeira é a contraposição de outros poderes ao burocrático, o que se pode chamar modernamente de sistema de freios e contrapesos. Assim, a solução para o caso do governo burocrático alemão seria a criação de "[...] mecanismos de controles mútuos entre burocracia, partidos, parlamentos, mercado, cidadãos/consumidores e líderes plebiscitários (Abrucio; Loureiro, 2018:33). As esferas da burocracia e da política deveriam ser complementares, para a manutenção das liberdades, mas também conflituosas, evitando a concentração indevida de poder. Conforme Abrucio e Loureiro (2018:33): "aos burocratas deve ser garantida autonomia para imprimir seu saber técnico na gestão do Estado e de suas políticas, contando que esse poder seja acompanhado de controles que evitem a constituição de uma tecnocracia, para usar um termo mais contemporâneo".

O fim dos modelos burocráticos de Estado Totalitário descritos por Arendt - Nazista e Comunista - de forma alguma significou o fim da burocracia como forma ou instrumento de exercício do poder político na modernidade. $\mathrm{O}$ adensamento do modo de produção capitalista na sociedade, com as revoluções tecnológicas do século $\mathrm{XX}$, resultou, mesmo dentro do Estado democrático, no surgimento da tecnocracia, em que o fortalecimento do Poder Executivo se dá pelo deslocamento das instâncias decisórias do Parlamento para órgãos técnicos (Jiménez, 2014:84), (Perissinotto, 2014:60). No Brasil, a criação desses órgãos 
caracterizou o nascimento de uma tecnoburocracia ligada ao governo federal. $\mathrm{O}$ Departamento de Administração do Serviço Público (DASP), criado em 1938, deu ao país as bases da institucionalização da burocracia, e foi um marco do início do insulamento burocrático brasileiro, processo apoiado pelas elites modernizantes também nos governos de JK e Médici (Oliveira, 2012).

A autonomia desses órgãos de controle frente ao Legislativo e sua subordinação ao Executivo "[...] seria uma forma de proteção do núcleo técnico da administração, permitindo a tomada de decisões e a implementação de projetos à revelia das interferências e disputas políticas" (Oliveira, 2012:38). Tal autonomia pode gerar arbitrariedades, e sua presença foi marcante nos períodos autoritários, em especial na Ditadura Militar brasileira, quando a classe política tradicional dos Ministérios foi substituída por tecnocratas.

Com o golpe de 1964, o Brasil passa a integrar a lista de regimes ditatoriais da América Latina. A legitimação do governo vem de um discurso patriótico e anticomunista, e de uma ideologia antipolítica e tecnoburocrática, alegando os ensejos de modernização do país. Para tanto, o aparato da administração pública foi fortalecido e aperfeiçoado, seja em órgãos como o Banco Central, como a Empresa Brasileira de Pesquisa em Agropecuária (Embrapa), seja com a criação do Instituto de Pesquisa Econômica Aplicada (Ipea) e por meio dos Planos Nacionais de Desenvolvimento (PNDs), entre outros (Abrucio; Pedroti; Pó, 2010).

Também se destaca, nesse período, uma intensificação do poder de intervenção do Estado, como jamais havia ocorrido. O governo militar buscou neutralizar as interferências político-partidárias, além de estabelecer um controle social pela coerção, criando o Serviço Nacional de Informações (SNI), em 1964, considerado exemplo da burocracia altamente insulada e influente nas searas política e social (Oliveira, 2012:40). Com os anos, o SNI tornou-se um órgão com funções distorcidas, manipulado pelo Poder Executivo em verdadeira disfunção burocrática. Viu-se em processo de enfraquecimento, reassumindo seu caráter estritamente burocrático em 1974, quando se iniciou o processo de distensão política de Geisel (Oliveira, 2012). Em 1979, criou-se o Programa Nacional de Desburocratização, que não foi bem-sucedido, mas preparou o terreno para ideias no processo de redemocratização do país (Abrucio; Pedroti; Pó, 2010).

Após a democratização e a Constituição de 1988, o poder burocrático exercido pela elite do funcionalismo público oscilou entre o aceite da tecnocracia pela adoção do modelo econômico neoliberal (Castelfranchi, 2008:21) e do corporativismo, contra os projetos de reforma do Estado (Bresser Pereira, 2007). 
Conforme apontado pelas primeiras análises de sua gestão, o governo de Jair Bolsonaro caracteriza-se pelo aparelhamento ideológico do Estado (Lynch, 2020:s/n) e por um projeto econômico justificado, por vezes, pela animosidade ao funcionalismo público (G1, 2020:s/n). Como exemplo, constata-se a extinção de dezenas de instâncias de caráter decisório, colegiado e técnico, no âmbito da Administração Pública, verticalizando as estruturas de decisão (Lynch, 2020:s/n), o que levou a burocracia da atual gestão a atuar por meio de normas como decretos e portarias, como será visto abaixo.

Passa-se assim a uma análise sobre o ordenamento jurídico nacional, sobre a burocracia, e acerca da postura da atual gestão do governo federal.

\section{O sistema legal brasileiro e o governo burocrático}

Nas premissas apontadas por Weber, nota-se que é numa sociedade ampliada, com participação social nas decisões do governo, que o autoritarismo é mitigado e a democracia se fortalece. Assim se garantem o respeito à supremacia do interesse público sobre o privado e a obediência à indisponibilidade do interesse público, os dois super princípios administrativos brasileiros, ou, na expressão de Bandeira de Mello (2014:55), as "pedras de toque do regime jurídico-administrativo". Com a boa técnica burocrática, salvaguardam-se os demais princípios do artigo 37 da Constituição Federal, em especial a eficiência e a legalidade. Assim, no ordenamento jurídico brasileiro, a edição de decretos, portarias e outros instrumentos do gênero é possível e legal, desde que obedeça a competência em pessoa e matéria, que possui previsão constitucional.

Sendo o Direito um sistema de normas, uma ordem normativa que regula as relações humanas e sociais, a compatibilidade das normas (ou seja, a coerência do ordenamento) é essencial. Ocorrendo incompatibilidade, uma das normas será excluída. A validade de uma norma não está apenas na autoridade competente, mas também na compatibilidade com outras normas; caso haja conflito, existe uma antinomia que deve ser resolvida, para manter a coerência (Cardoso, 2012). Para solucionar as possíveis antinomias, há critérios para determinar qual norma prevalecerá. Assim se estabelecem, como base, os critérios hierárquico, cronológico e de especialidade. O critério hierárquico é o prevalente, e tal hierarquia consta no artigo 59 da Constituição Federal (CF).

Nesse raciocínio, o Brasil tem a Constituição como norma máxima, e abaixo, por ordem, as leis complementares, ordinárias, delegadas, medidas provisórias, decretos 
legislativos e resoluções. Esses instrumentos são os atos legislativos que compõem o ordenamento jurídico brasileiro, pelo qual se criam direitos e obrigações.

Conforme a doutrina jurídica, sob as resoluções estão os decretos do Poder Executivo, as portarias e os demais atos normativos da administração pública. Esses instrumentos estão na seara do direito administrativo, é por meio deles que a administração pública expressa o poder regulamentar. Conforme doutrina de Di Pietro (2014:92), o poder regulamentar é: “[...] uma das formas pelas quais se expressa a função normativa do Poder Executivo. Pode ser definido como o que cabe ao Chefe do Poder Executivo da União, dos Estados e dos Municípios, de editar normas complementares à lei, para sua fiel execução". O poder regulamentar só pode ser exercido quando a lei não esgota a matéria. Em todos os instrumentos citados, não lhes é possibilitado contrariar a lei, criar direitos, obrigações, proibições, e/ou penalidades que não estejam previstos em lei. Caso o façam, ferem o princípio da legalidade dos atos da administração (art. 37, caput, $\mathrm{CF})^{3}$.

Apesar de essa ser a pirâmide normativa brasileira, com os decretos e portarias do Poder Executivo como os instrumentos mais residuais, constitucionalmente impossibilitados de versar sobre matéria legal, o atual governo tem insistido em utilizá-los dessa forma. Isso tem contrariado a Constituição e as disposições legais que já existem sobre muitos temas, inclusive o migratório.

Deve-se estar atento aos sinais autoritários que um governo dá em um momento como o que vivemos. Além das portarias, que são objeto direto desta pesquisa, o atual governo se utiliza de decretos presidenciais para tentar alterar disposições legais em outros temas. A exemplo, citam-se os decretos presidenciais 10.627/21, 10.628/21, 10.629/21 e 10.630/21, publicados em 12 de fevereiro de 2021, que alteram o Estatuto do Desarmamento. Até então, congressistas já protocolaram 30 pedidos de anulação dos decretos, sob argumento de que o executivo usurpou matéria de competência do Poder Legislativo (Souza, 2021). Os decretos 9.785/2019 e 9.787/2019, que flexibilizavam o uso de armas, também foram questionados sobre sua constitucionalidade, no mesmo sentido (abuso de poder regulamentar em matéria de lei) (Brandão; Capecchi, 2019).

\footnotetext{
${ }^{3}$ A autora esclarece que existem dois tipos de regulamento. O executivo, explicado no texto, e o autônomo, que é independente de lei prévia e inova no ordenamento jurídico: "No direito brasileiro, a Constituição de 1988 limitou consideravelmente o poder regulamentar, não deixando espaço para os regulamentos autônomos, a não ser a partir da Emenda Constitucional n ${ }^{\circ}$ 32/01. Na Constituição de 1967, com redação dada pela Emenda Constitucional $\mathrm{n}^{\circ} 1 / 1969$, o artigo 81, V, outorgava competência ao Presidente da República para 'dispor sobre a estruturação, atribuições e funcionamento dos órgãos da administração federal', única hipótese de decreto dessa natureza agasalhada expressamente na legislação; tratava-se de decreto autônomo sobre matéria de organização da Administração Pública. A atual Constituição, no artigo 84, VI, previa, na redação original, competência para 'dispor sobre a organização e o funcionamento da administração federal, na forma da lei" ' (Di Pietro, 2014:93).
} 
Considerando o primeiro ano de seu governo, Bolsonaro foi o presidente que mais editou decretos: 537 só em 2019. Cinco desses foram alvo de (dezesseis) ações perante o Supremo Tribunal Federal (STF): sobre cortes na educação, extinção dos conselhos, escolha de reitores das universidades, que alterava o Fundo Nacional do Meio Ambiente, além do decreto de armas, já mencionado (Oliveira et. al, 2020). O decreto dos Conselhos também foi declarado pelo STF como excessivo do ponto de vista regulamentar: não é possível ao presidente do executivo extinguir, por meio de decreto, conselhos que foram criados por meio de lei (STF, 2019). O que se conclui é que o chefe do executivo federal tem tentado legislar por meio de decretos, excedendo o poder regulamentar do cargo. Assim, os ministros têm seguido o mesmo caminho, tentando legislar (em simetria), por meio de portarias ministeriais. Em entrevista, o cientista político Carlos Melo explicou a preferência do presidente da República por tais instrumentos:

\begin{abstract}
A MP vai para o Congresso, se cria uma comissão especial, ela tem prazo de validade. Como funciona o decreto? $\mathrm{O}$ decreto não passa por esse trâmite legislativo - pode ser contestado depois. Decretos, portarias são medidas administrativas em que você não depende do Legislativo. É um governo que quer ter maior autonomia em relação ao Legislativo, maior distância, quando na verdade deveria ter um fator diferente, de compartilhamento com o Poder Legislativo (Oliveira et. al, 2020:s/n).
\end{abstract}

Considerando as preferências do atual governo pelos decretos, a fim de driblar o sistema legislativo, e a conjuntura pandêmica que o país tem enfrentado, o que a edição de portarias com disposições contra legem (e o seu cumprimento pelas autoridades) pode sinalizar para o Estado e a democracia, e como isso impacta as migrações no Brasil? Passamos a esclarecer as disposições constitucionais e legais sobre o tema, e uma análise geral das portarias, com o intuito de responder a essa questão.

\title{
A legislação migratória brasileira
}

Em tema migratório, o Brasil adotou importantes instrumentos, que foram assimilados no ordenamento interno com hierarquia de lei ordinária. Aderiu ao Tratado internacional da Convenção sobre os Refugiados de 1951, e ao Protocolo Adicional de 1967; promulgou a Lei 9474/97 (lei de Refúgio Brasileira) e a Lei 13.445/2017 (Lei de Migração), que é regulamentada pelo Decreto $\mathrm{n}^{\circ}$ 9.199, de 20 de novembro de 2017. A lei de Migração substituiu a Lei 6815/1980 (Estatuto do Estrangeiro), elaborada e promulgada na Ditadura Militar (1964-1985), que estabelecia como objetivo da imigração a mão-de-obra especializada, voltada para o desenvolvimento econômico, tecnológico e financeiro nacional 
(art. 16). Os princípios que guiavam a aplicação do Estatuto do Estrangeiro eram: segurança nacional, organização institucional, interesses políticos, socioeconômicos e culturais brasileiros, e defesa do trabalhador nacional (art. $2^{\circ}$ ). As medidas dessa lei eram restritivas e rígidas, e, ao longo do texto, destaca-se a preocupação com os interesses nacionais, um conceito aberto utilizado para limitar os direitos dos imigrantes (Claro, 2020).

Com a promulgação da Nova Carta Constitucional, em 1988, e com as alterações globais nos fluxos migratórios, o antigo estatuto tornou-se obsoleto, por não acompanhar as novas demandas que se apresentavam ao Estado brasileiro. Diante da necessidade de se estabelecer um novo marco legal migratório, com os grandes fluxos vindos do Haiti regulamentados por meio de normativas infralegais, passou-se a discutir junto à sociedade civil, por meio de conferências, a criação de uma nova lei migratória (Fernandes; Faria, 2017). O resultado foi a promulgação da Lei 13.445/2017.

A nova lei é pautada no respeito aos direitos humanos e garante aos imigrantes os mesmos direitos fundamentais de que desfrutam os brasileiros, em obediência às disposições constitucionais. Conforme Claro (2020:45): “Também recorre às normas infraconstitucionais de direitos humanos, aos tratados internacionais ratificados pelo Brasil e aos princípios e costumes do direito internacional em matéria de direitos humanos [...]". A lei 13.445/17 reconhece a migração como um direito humano, garante direitos individuais e sociais aos imigrantes, e lança a previsão de uma política pública migratória. Assim se conclui que a alteração legal é também uma mudança paradigmática no tratamento do tema.

Em janeiro de 2019, com a mudança de governo e com a posse do presidente Jair Bolsonaro, notou-se que o tratamento sobre o tema migratório mudaria: Bolsonaro confirmou a decisão pela saída do Pacto Global de Migração. O Pacto Global para uma Migração Segura, Ordenada e Regular foi adotado por 164 países na conferência intergovernamental de Marrakesh - Marrocos, em 2018, sob as recomendações da Assembleia Geral das Nações Unidas (ONU). É uma resposta internacional à atual crise migratória, seu texto é não vinculativo (não existem penalidades aos países que descumprirem as cláusulas), caracterizando-se como um instrumento de compromisso político (Garcia, 2019).

Assim não interfere nas políticas migratórias dos Estados e não exige contribuições financeiras. Tem como objetivo servir de guia para as medidas dos Estados sobre controle de migração irregular, combate às quadrilhas de tráfico de pessoas e imigração clandestina. Além disso, visa à criação de banco de dados, ao estabelecimento de instrumentos de cooperação entre os países, ao combate à xenofobia, à redução das vulnerabilidades dos imigrantes (de 
modo amplo, desde documentação até integração na sociedade receptora), entre outros (Garcia, 2019).

O governo federal brasileiro apontou o Pacto como inadequado para o tratamento do tema, considerando que a migração não deveria ser tratada como problema global, mas, dentro da soberania de cada país. Para o então Ministro das Relações Exteriores Ernesto Araújo (2019:s/n), a imigração não deve ser indiscriminada: "Tem de haver critérios para garantir a segurança tanto dos migrantes quanto dos cidadãos do país de destino. A imigração deve estar a serviço dos interesses nacionais e da coesão de cada sociedade".

O que se depreende dessa primeira fala do novo governo é que o discurso de interesse nacional foi resgatado do Estatuto revogado, ainda que a prioridade da nova lei seja a garantia de direitos humanos aos imigrantes. Posteriormente, em 23 de julho de 2019, o então Ministro Sérgio Moro editou a Portaria 666, a qual dispunha sobre os seguintes temas: impedimento de ingresso, repatriação, deportação sumária de pessoa perigosa, ou de pessoa que tenha praticado ato contrário aos princípios e objetivos dispostos na Constituição Federal.

Dentre as polêmicas geradas por tal instrumento, destacamos nesta oportunidade somente dois aspectos que foram criticados no âmbito jurídico: a criação do instituto de deportação sumária ( $\left.\operatorname{art} .2^{\circ}, \S^{\circ}\right)$ e previsão de prisão cautelar para fins de deportação $\left(\operatorname{art.} 5^{\circ}\right)$, o que é contra legem. A deportação sumária não tem previsão legal, e uma portaria interministerial não é instrumento legal adequado para tanto, uma vez que sua aprovação demanda o processo legislativo de lei ordinária. A prisão para fins de deportação não é prevista em lei, e tal medida também pede previsão legal (DPU, 2019). Assim, trata-se de uma portaria de Ministério (poder normativo da Administração) que extrapola sua competência regulamentar, ao versar sobre tema que demanda ato legislativo.

Com a proposição de Ação de Descumprimento de Preceito Fundamental (ADPF) perante o STF, em setembro de 2019, o Ministro da Justiça revogou a Portaria, editando uma nova (770/2019), mais branda, regulamentando a deportação, mas sem prever deportação sumária e prisão cautelar para deportação (CONJUR, 2019). Apesar da aparente superação de tal impasse, em 2020, a pandemia de Covid-19 demandou um maior controle de fronteiras com fins epidemiológicos. Essa situação possibilitou ao governo federal retomar alguns pontos polêmicos da portaria 666/2019, especialmente os referentes à deportação sumária de imigrantes. 


\section{As portarias restritivas de circulação na pandemia de Covid-19 e as ações judiciais opostas}

Em março de 2020, o fechamento de fronteiras foi uma medida adotada por grande parte dos países, a fim de limitar a circulação de pessoas e a propagação do vírus. No Brasil, o Congresso editou a lei 13.979/2020, a Lei de Quarentena, em fevereiro de 2020. Em março, reconheceu o estado de calamidade pública pelo Decreto Legislativo 06/2020. Regrando o fechamento de fronteiras, os Ministérios da Justiça, da Saúde e da Casa Civil editaram, em 17 de março de 2020, a Portaria 120/2020. Foi a primeira medida excepcional e temporária da restrição de entrada no Brasil por imigrantes da Venezuela (e apenas desse país), conforme recomendação da Agência Nacional de Vigilância Sanitária (Anvisa).

A normativa seria seguida de dezenas de outras portarias. Conforme se verifica no site do Planalto, foram editadas, desde então, as seguintes portarias: 125, de 19/03/2020 (restringindo o ingresso de imigrantes da Argentina, Bolívia, Colômbia, Guiana Francesa; Guiana, Paraguai, Peru e Suriname). 126, 19/03/2020 (restringindo o ingresso de imigrantes da China, da União Europeia (UE), da Islândia, da Noruega, da Suíça, do Reino Unido, da Austrália, do Japão, da Malásia e da Coreia do Sul). 132, de 22/03/2020 (restrição da migração do Uruguai). 133, de 23/03/2020. 47, de 26/03/2020 (restrição a todas as nacionalidades, via transporte aquaviário). 149, de 27/03/2020 (restrição a todas as nacionalidades, via transporte aéreo). 152, de 27/03/2020 (prorroga prazo da anterior e estabelece as exceções). 158, de 31/03/2020 (prorroga restrição aos venezuelanos). 8, de 02/04/2020 (prorroga restrição da 125). 195, de 20/04/2020 (prorroga restrição ao Uruguai). 201, de 24/04/2020 (prorroga a restrição para entrada via aquaviária). 203, de 28/04/2020 (prorroga a restrição para entrada via aérea). 204, de 29/04/2020 (restrição via terrestre a qualquer nacionalidade). 255, de 22/05/2020 (trata de restrições ao ingresso por via terrestre, aquaviária e aérea, a qualquer nacionalidade). 319, de 20/06/2020 (prorroga a restrição da anterior). 340 de 30/06/2020 (prorroga as restrições ao ingresso por via terrestre, aquaviária e aérea, a qualquer nacionalidade). Por fim, a portaria conjunta 1/2020, de 29/07/2020 (trata de restrições nas vias terrestres e aquaviárias, autorizando a entrada via aérea).

Essa foi a última portaria editada até a proposição de Ação Civil Pública (ACP) ${ }^{4}$ pela Defensoria Pública da União, pelo Ministério Público Federal, pela Associação Direitos Humanos em Rede (Conectas Direitos Humanos) e pela Cáritas Arquidiocesana de São Paulo, contra tais atos normativos da União. A ação foi proposta tendo em vista um dispositivo que

\footnotetext{
${ }^{4}$ Autos 1004501-35.2020.4.01.3000, da $3^{\text {a }}$ Vara Federal Cível e Criminal da SJAC (TRF 1 ${ }^{a}$ Região).
} 
se repete em todas as portarias em questão: as sanções de responsabilização civil, administrativa e penal, repatriação ou deportação imediata e inabilitação de pedido de refúgio dos imigrantes que descumprirem as restrições da(s) portaria(s). Com tais sanções, verifica-se que não somente o ingresso de imigrantes no país foi restringido, mas que se abriu uma possibilidade de retirar compulsoriamente aqueles que entrarem no país de forma irregular, o que contraria disposições da Lei 13.445/17. Tal medida vinha sendo tomada pelo governo federal, ainda que todas as portarias citadas assegurassem que a restrição prevista não impedia a execução de ações humanitárias transfronteiriças (desde que a execução fosse previamente autorizada pelas autoridades sanitárias locais).

A petição inicial, que conta com 53 páginas, destaca várias questões jurídicas, sociais e humanitárias que são extremamente importantes, fatos que violam tratados internacionais, a Lei de Migração e a Lei de Refúgio. Nos fatos que embasam a causa, está descrita a situação migratória da região de fronteira do Estado do Acre, onde centenas de imigrantes do Peru e Bolívia buscaram ingressar desde março de 2020, quando foi declarado o estado de pandemia. Com o fechamento da fronteira baseado nas portarias, muitos imigrantes acabaram "ilhados", porque nenhum Estado os acolhia. A inicial cita a deportação sumária de um grupo de 18 pessoas, composto em quase sua metade de crianças e de adolescentes, que, após atravessarem o Rio Acre e realizar entrevista com a Polícia Federal, “[...] foram sumariamente deportados, postos numa van e deixados à própria sorte na Ponte de Assis Brasil, numa "prisão sem grades": não poderiam nem retornar ao Peru, nem "entrar" no Brasil - a despeito de faticamente nele estarem" (2020:6).

A ação também menciona um outro grupo composto de duas mulheres e de seis crianças que tiveram exatamente o mesmo destino, em agosto. Não são casos isolados, e continuam acontecendo em todo o país: um terceiro grupo de 18 venezuelanos estava na iminência de receber ordem de deportação na data da propositura da ação, e o grupo contava com uma gestante e crianças. Os casos vão sendo judicializados individualmente, pela Defensoria Pública, pois se tratam de "abusos e arbitrariedades" cometidos pelo Poder Executivo federal. São as medidas cabíveis, porém é contraproducente ao trabalho da Defensoria, pois são dezenas de casos que continuam se repetindo.

Juridicamente, a ação se baseia nos argumentos de que a União extrapolou o poder regulamentar nas portarias (relembra-se, conforme anteriormente exposto, que "portaria" não é sequer ato normativo legislativo, não sendo possível estabelecer direitos e deveres por meio desse instrumento). Havia uma iminente ordem de deportação dos imigrantes que estavam na 
fronteira do Acre, o que viola diversos dispositivos legais ${ }^{5}$ (além das deportações que ocorreram anteriormente), como a não criminalização do imigrante, a promoção da entrada regular, e a proibição de deportação coletiva. A Lei de Migração também assegura o acesso do imigrante ao devido processo legal e à ampla defesa. A Lei de Refúgio ainda determina que a deportação de solicitante de refúgio jamais será feita pela fronteira de um país onde sua vida ou liberdade estejam ameaçadas (o que se chama non-refoulement). Ademais, determina que, ainda que o ingresso do indivíduo tenha sido feito de modo irregular, isso não será impedimento para solicitação de refúgio (arts. $7^{\circ}$ e $8^{\circ}$ ). A Convenção Americana de Direitos Humanos (CADH) tem disposições no mesmo sentido.

A inicial também destaca que não existe, no ordenamento jurídico brasileiro, a possibilidade de "deportação imediata" tal qual as portarias tentam instituir. Invoca a proteção à criança e ao adolescente, que é constitucional, prevista em tratados internacionais e em Estatuto próprio (o Estatuto da Criança e do Adolescente), visto que muitos dos imigrantes que estão na fronteira são menores de idade. Assim, a situação de ilegalidade das deportações se agrava, considerando que se atenta contra um grupo ainda mais vulnerável.

Por fim, a Defensoria e demais autores destacam, na fundamentação jurídica, a possibilidade e necessidade da compatibilização entre os controles sanitários e migratórios na região de fronteira, e a garantia de direitos humanos aos imigrantes. A inabilitação ao pedido de refúgio aos que ingressarem no território brasileiro é criação de penalidade não prevista em lei, e o estado de calamidade causado pela pandemia não gera um estado de exceção generalizado:

[...] o estado de calamidade pública decorrente da pandemia de COVID-19 não inaugurou um Estado de Exceção onde normas e princípios fundacionais do Estado Democrático de Direito estejam suspensos ou condicionados ao livre arbítrio dos órgãos do Poder Executivo.

[...].

Não nos situamos, pois, em um estágio de excepcionalidade institucional no qual o Poder Judiciário e o Poder Legislativo perderam suas prerrogativas e poderes constitucionalmente assegurados. Logo, o Poder Executivo e seus órgãos não possuem discricionariedade e poder de decisão sobre a violabilidade de direitos humanos de primeira dimensão (SJAC, 2020:28).

\footnotetext{
5 Art. $3^{\text {o }}$ A política migratória brasileira rege-se pelos seguintes princípios e diretrizes: I - universalidade, indivisibilidade e interdependência dos direitos humanos; (...) III - não criminalização da migração; IV - não discriminação em razão dos critérios ou dos procedimentos pelos quais a pessoa foi admitida em território nacional; V - promoção de entrada regular e de regularização documental; VI - acolhida humanitária; (...) XVII proteção integral e atenção ao superior interesse da criança e do adolescente migrante; (...) XXII - repúdio a práticas de expulsão ou de deportação coletivas.
} 
$\mathrm{O}$ artigo $1^{\circ}$ do Código Penal $(\mathrm{CP})$ dispõe que não há crime sem lei anterior que o defina, nem pena sem prévia cominação legal. Não sendo uma portaria um ato legislativo, é impossível a instituição desse tipo de penalidade, o que reforça a ilegalidade dos atos do governo federal. Todos esses argumentos caracterizam as portarias como "aberrações normativas", conforme denominado na petição inicial em análise.

O Alto Comissariado das Nações Unidas para Refugiados (ACNUR) e a OMS elaboraram documentos que orientam os Estados em relação aos direitos migratórios e à questão sanitária provocada pela pandemia. Por tais orientações, a compatibilização deve ser realizada, é possível e necessária, em especial com a realização de exames, testagem e quarentena.

A ação, que foi proposta em agosto de 2020, teve deferido liminarmente o pedido de tutela de urgência de suspensão dos atos de deportação e repatriação ou outra medida compulsória para retirada de imigrantes do território, que estejam em condição de vulnerabilidade e que sejam solicitantes de acolhida humanitária ou refúgio (decisão de 19/08/2020). Porém, a ação ainda está em andamento, de modo que a situação ainda não foi resolvida, e todas as demais portarias posteriores continuam reiterando as mesmas disposições apontadas como ilegais pelos autores da ação.

As normativas posteriores, até a construção desta pesquisa, são as seguintes portarias: $\mathrm{n}^{\text {o }} 419$ de 26/08/2020 (trata de restrições ao ingresso por via terrestre, aquaviária a qualquer nacionalidade pelo prazo de 30 dias, permitindo a entrada via aérea). $\mathrm{N}^{\circ} 456$ de 24/09/2020 (prorroga a restrição da portaria anterior). $\mathrm{N}^{\circ} 470$ de 02/10/2020 (prorroga a restrição das anteriores). $N^{\circ} 478$ de 14/10/2020 (prorroga a restrição das anteriores). $N^{\circ} 518$ de 12/11/2020 (prorroga a restrição das anteriores) $N^{\circ} 615$ de 11/12/2020 (prorroga a restrição das anteriores), e as de números 630 (de 17/12/2020), 648 (de 23/12/2020), 651 (de 08/01/2021), 652 (de 25/01/2021), todas tratando de restrições ao ingresso por via terrestre e aquaviária a qualquer nacionalidade, permitindo a entrada por via aérea, sem estabelecer prazo final.

Além das deportações mencionadas na Ação Civil Pública em questão, muitas deportações foram reportadas pela imprensa. As entradas pela fronteira com o Acre se repetem, da mesma forma que as deportações. Em análise a dados da Polícia Federal obtidos por meio da Lei de Acesso à Informação, a imprensa constatou que as deportações realizadas no período de abril a julho de 2020 aumentaram 9.200\% comparadas com os números do ano de 2019 (oito pessoas entre abril/julho de 2019, em comparação a 744 do mesmo período de 2020) (OVALE, 2020). 
As nacionalidades predominantes foram os bolivianos, venezuelanos e paraguaios, que entraram majoritariamente pelas cidades de Corumbá-MS, região de fronteira com a Bolívia, e Pacaraima-RA, que faz fronteira com a Venezuela (OVALE, 2020). De acordo com especialistas entrevistados, as portarias federais têm grande impacto nesse aumento de deportações. Conforme o Padre Bobadilla, coordenador da Pastoral do Migrante em Pacaraima: "Cresceram (as deportações) porque o governo criou essas deportações. A Polícia Federal está fazendo o que o governo mandou" (OVALE, 2020:s/n).

No site da Polícia Federal, ainda, verificou-se notícia publicada em novembro de 2020 sobre a deportação imediata de 196 bolivianos que ingressaram no Brasil em Corumbá-MS. Relata a notícia que os imigrantes estavam em seis ônibus, e que a Polícia Federal tomou declarações de alguns bolivianos, a fim de apuração de migração ilegal (art. 232-A, CP). Ainda registra que as deportações realizadas foram baseadas na Portaria 518/2020 da Presidência da República (Polícia Federal, 2020).

Por fim, cita-se a notícia mais recente, de janeiro de 2021, sobre a deportação de 55 indígenas Warao (destes, 32 são crianças) que ingressaram em Pacaraima-RA via terrestre. Conforme informado pela Defensoria Pública e Ministério Público Federal, a deportação sumária ocorreria no mesmo dia, sem qualquer análise do caso, condições de saúde e demais vulnerabilidades. Os indígenas venezuelanos foram detidos pelo exército e levados à delegacia da Polícia Federal, “[...] que informou ao MPF ter iniciado procedimento para 'deportação imediata', conforme previsto no Artigo 8 da Portaria 648/2020, da Casa Civil, que dispõe sobre restrições à entrada de estrangeiros em razão da pandemia de covid-19." (Pontes, 2021:s/n).

$\mathrm{O}$ caso foi levado à justiça e, em decisão preliminar, o magistrado suspendeu a deportação e a aplicação da portaria. Sua decisão foi fundamentada na falta de lastro legal da normativa, na aplicação de princípios constitucionais a todos os seres humanos que estiverem em território brasileiro, destacando o devido processo legal e ampla defesa, e que a contenção do vírus é importante, mas não pode ser buscada a qualquer custo (Pontes, 2021).

Pelos fatos narrados, nota-se que as portarias dos Ministérios do Governo Federal têm sido cumpridas, apesar de contrariarem toda a legislação migratória, tratados internacionais e a própria Constituição Federal, pois ferem o princípio da legalidade dos atos da Administração Pública (art. 37) ao instituir proibições e penalidades que não existem em qualquer lei brasileira. Assim, a deportação imediata é instituto criado pela portaria, e as penalidades são contra legem. 
Para além do contexto fático de casos individuais que têm se vislumbrado e recorrentemente solucionado no Poder Judiciário, dada sua gravidade e desrespeito à legislação vigente, é necessária a reflexão sobre as implicações que a edição de tais portarias podem gerar no cenário social, jurídico e político do Brasil. A Lei de Migração de 2017 se alinha aos preceitos constitucionais e de tratados internacionais de direitos humanos. Possibilitadas pelo contexto excepcional de pandemia, as portarias em comento resgatam o discurso nacionalista do Estatuto do Estrangeiro, da Ditadura Militar, tal qual a tentativa da Portaria 666/2019.

Retomando Arendt (1989), outra característica clássica dos governos autoritários é o nacionalismo exacerbado. As correntes nacionalistas (em nível global) ganharam uma nova oportunidade de ascensão ao longo da pandemia. Bieber (2020) discrimina quatro aspectos da conjuntura pandêmica que podem refletir num aumento das práticas nacionalistas excludentes da extrema direita. O primeiro é a trajetória que os movimentos nacionalistas tiveram antes da pandemia; o segundo, a relação entre o nacionalismo excludente, populismo, e o aumento do autoritarismo, que acontece na medida em que os governos suspendem ou reduzem as liberdades democráticas e civis. Numa pandemia, isso é facilitado, o que gera uma política de emergência (que foi utilizada, por exemplo, para instituir o governo nazista). Um governo autoritário se baseia em emergências para suspender as instituições democráticas e seus freios e contrapesos, de forma desproporcional ao que a situação demandaria.

O terceiro aspecto é o aumento de preconceitos contra alguns grupos associando-os à pandemia (como portadores de doenças, e a consequente marginalização embasada em argumentos de higiene pública e do controle da propagação de doença), o que reflete no quarto aspecto: o aumento das fronteiras, a desglobalização, e a política do medo (que culpa minorias pela doença) (Bieber, 2020). As restrições em fronteiras são temporárias, e seu enrijecimento permanente não é realístico. A disseminação da Covid-19 pelo mundo, apesar das medidas repressivas intensas nas fronteiras, demonstrou que esse controle por si só não é capaz de deter a doença.

Por fim, a política do medo consiste na exploração, por extremistas, de teorias da conspiração, culpando grupos étnicos pela doença, buscando o caos e a anarquia para a implementação de uma nova ordem política. Apesar de não acreditar na ruína da globalização, nem em fronteiras mais fortes a longo prazo, o autor reconhece que a abertura das fronteiras será um processo demorado. De outro lado, os medos e preconceitos alimentados nesse período poderão moldar o mundo pós-pandêmico, e a utilização de imigrantes e outras minorias como bode expiatório vai aumentar sua exclusão (Bieber, 2020). 
Conforme Ruseishvili (2020), a decisão do governo brasileiro de fechar a fronteira com a Venezuela no início da pandemia já mostrou sua motivação ideológica, pois o número de infectados pela doença no Brasil já era muito maior que no país vizinho. Além de agravar o percurso migratório terrestre para vias arriscadas, a restrição de entrada por vias aéreas se deu muito tempo depois de o vírus ter sido importado da Europa por viajantes. Assim, a restrição de fronteiras da pandemia já demonstra as desigualdades sistêmicas na mobilidade e na imobilidade humanas. Essa desigualdade torna ainda mais difícil pensar em previsões sobre o futuro das migrações no mundo pós pandêmico.

$\mathrm{Na}$ retromencionada $\mathrm{ACP}$, os autores repisam que o estado de calamidade da pandemia não inaugura um Estado de Exceção pelo qual os Poderes Judiciário e Legislativo perderiam suas prerrogativas, estando os direitos individuais fundamentais ao arbítrio do Executivo. De acordo com a ação proposta, as portarias objetivam muito mais a inviabilização de pedidos de refúgio do que a contenção do vírus:

\footnotetext{
Em resumo: as legítimas preocupações com a saúde pública devem ser abordadas ao mesmo tempo em que são preservados os padrões de proteção garantidos às pessoas em situação de refúgio. Num país que tem mais de 100.000 (cem mil) mortes causadas pela pandemia de COVID-19, que não implantou medidas de isolamento social compulsório no momento adequado, que não criou nenhum protocolo de quarentena para viajantes vindos do exterior, e que em nenhum momento se preocupou com a transmissão descontrolada do vírus em seu território, tornando-se um dos epicentros globais da pandemia e verdadeira ameaça à saúde global, é irracional e despropositado impedir a entrada de pessoas miseráveis e vulneráveis, sob o frágil argumento de proteção abstrata da saúde pública (SJAC, 2020:28).
}

Com os acontecimentos mais recentes, o argumento exposto torna-se ainda mais forte. Isso porque o governo federal tem demonstrado absurda morosidade em relação à negociação de vacinas, além de desestimular uso de máscaras, distanciamento social, e promover uso de medicamento como tratamento precoce que não tem o mínimo respaldo médico-científico. Não parece, pelos demais fatos que se somam à conjuntura brasileira, que exista um interesse na saúde pública. O fechamento de fronteiras no Brasil é muito mais um projeto político autoritário de contenção migratória do que de prevenção sanitária. E as portarias interministeriais ora analisadas são um instrumento burocrático, que não respeita o bloco de constitucionalidade e as normas infralegais; é a burocracia sendo usada pelo poder político para subverter o sistema legal.

Não bastasse a conjuntura da região norte do país, verificou-se que a fronteira com o Paraguai, por exemplo, foi reaberta em 14 de outubro de 2020, pela Portaria $n^{\circ} 478$. Conforme artigo $6^{\circ}$, as restrições da Portaria não afetam o ingresso de estrangeiros por via terrestre entre o Brasil e o Paraguai, observados os demais requisitos migratórios exigidos. 
O dispositivo foi mantido pelas outras portarias subsequentes, e o protocolo sanitário do Paraguai determina que o trânsito é válido para as pessoas com documento de identidade da cidade de Foz do Iguaçu, e a abertura da fronteira ocorre das $05 \mathrm{~h}$ até $14 \mathrm{~h}$, somente para veículos. O uso de máscaras é obrigatório e a passagem a pé está proibida. Para turistas “[...] é exigido seguro médico internacional que inclua testes de covid-19 e internações em UTI (unidade de terapia intensiva). A saída poderá ser feita em qualquer horário. Para turistas e comerciantes, a circulação é autorizada em um raio de até 30 quilômetros de Cidade do Leste" (Garrett Jr., 2020:s/n). Ainda, conforme o site Jornal da Cidade - Foz do Iguaçu (2020), houve uma pressão intensa do empresariado da região pela reabertura da fronteira, devido aos impactos econômicos.

É evidente que o fechamento de fronteiras causa impacto econômico, especialmente quando se tem em vista que são cidades gêmeas e a circulação de mão-de-obra é significativa na região. Por outro lado, o que se questiona é a preocupação somente com casos de abertura quando pressionados pelo mercado, por interesses econômicos, enquanto as mesmas portarias atacam o direito de refúgio e fecham fronteiras para um grupo com vulnerabilidades sobrepostas no Norte brasileiro. Ademais, salienta-se que as medidas sanitárias foram determinadas somente pelo Paraguai, não sendo uma preocupação do governo federal brasileiro.

Ao analisar o impacto da Covid-19 nos países da América Latina, Gargarella (2020) ressalta que é difícil explicar as diferenças entre o número de mortes dos países sem traçar um paralelo com o caráter ultrajante de algumas decisões presidenciais. O número elevado de mortes no Brasil, em comparação à Argentina (países vizinhos, semelhantes nos quesitos de desenvolvimento econômico, níveis de desigualdade e história política), dá-se pela postura irracional do Presidente da República brasileiro frente à pandemia. Por exemplo, suas aparições na mídia usando frases como "volte ao trabalho", e "pessoas morrem, é a vida", além de chamar a doença de "gripezinha". Assim como Trump, Bolsonaro é exemplo de uma administração pautada em decisões erráticas, infundadas e contraditórias: "President Bolsonaro has pursued capricious responses to the crisis, with catastrophic results. As an oped from the scientific magazine The Lancet put it, "perhaps the biggest threat to Brazil's COVID-19 response is its president, Jair Bolsonaro. "." (Gargarella, 2020:67).

\footnotetext{
${ }^{6} \mathrm{O}$ presidente Bolsonaro buscou respostas caprichosas à crise, com resultados catastróficos. Como disse um artigo da revista científica The Lancet, "talvez a maior ameaça à resposta da COVID-19 do Brasil seja seu presidente, Jair Bolsonaro" (tradução nossa).
} 
A vivência do contexto pandêmico no Brasil não tem sido fácil, tanto para brasileiros quanto para imigrantes. Tem-se vislumbrado uma tentativa de mudança nas entradas de imigrantes e refugiados, retomando disposições legais que não se enquadram no sistema jurídico, e a luta pela efetividade dos direitos migratórios tem se concentrado em instituições da sociedade civil e do poder público, como a Defensoria Pública e o Ministério Público. É necessário resistência, a fim de que o futuro pós-pandêmico seja democrático e nãoexcludente, para todos.

As mudanças nos processos migratórios não ocorrem somente por causa do controle epidemiológico causado pela pandemia, mas também pelo pano de fundo de ideologias e posicionamentos políticos mais amplos. O que se tem vislumbrado no Brasil é um estado de alerta referente à ordem migratória, mas ainda mais iminente, uma ameaça à ordem democrática.

\section{Considerações finais}

Pelo panorama dado, nota-se que as restrições de fronteiras que estão sendo promovidas no Brasil ocorrem por fatos relacionados a ideologias políticas nacionalistas e autoritárias, retomadas do Regime Militar. Falar em uma nova ordem migratória com o contexto brasileiro talvez seja prematuro, pois não se refere diretamente ao controle epidemiológico e de circulação de pessoas, mas ao próprio Estado Democrático de Direito.

Relembra-se que as soluções apontadas por Weber para não se chegar a uma autocracia eram a contraposição de outros poderes ao burocrático, mantendo a complementaridade entre burocracia e política, mas de forma que elas ainda fossem conflituosas, para não ocorrer alguma concentração indevida de poder. Com poderes que se contrapõem de forma dialética, e uma sociedade civil ampliada, garante-se que o autoritarismo não dominará o Estado. A pressão vinda da sociedade civil é essencial contra atos burocráticos que contrariem o ordenamento jurídico. Ser conivente com a ilegalidade abre espaço para que novos atos autoritários se consolidem. No caso brasileiro, as portarias ministeriais são atos burocráticos que excedem exageradamente sua competência legal.

Porém, os atos administrativos da União têm encontrado resistência pelas ações propostas pela Defensoria Pública da União, pelo Ministério Público Federal, e pela sociedade civil, representada por organizações civis que cuidam de interesses dos imigrantes. Os dois primeiros são, constitucionalmente, instituições permanentes e essenciais à defesa do Estado Democrático de Direito (arts. 127 e 134, CF). 
Se um governo burocrático cresceu dentro da Alemanha sob os avisos de Weber, é primordial à defesa da ordem democrática brasileira que a Constituição e o sistema legal sejam respeitados. Visto a quantidade de deportações (ilegais) que tem sido realizada no Norte do país, a propositura de inúmeras ações pelo Ministério Público Federal e Defensoria da União, e o acolhimento praticamente unânime dos pedidos em tutela de urgência pelo Judiciário, pode-se concluir que há uma situação social e jurídica bastante crítica no que se refere ao tema migratório. Portanto, a ilegalidade tem se mostrado evidente aos olhos dos altos cargos do judiciário brasileiro. Se as portarias são declaradas como "aberrações jurídicas" tamanho descompasso com o sistema jurídico, a contraposição de poderes deve se fazer forte, sob pena de a nova ordem migratória regredir seriamente no Brasil, e de os processos participativos e democráticos sofrerem um ataque difícil de ser revertido.

Num contexto que se altera diariamente, a pesquisa fica limitada aos acontecimentos que já se consolidaram, ainda estando por vir novas portarias regulamentando o tema, além, claro, da expectativa do controle da pandemia. A retomada do processo de reabertura de fronteiras é certa, porém sem data prevista; a partir desses novos eventos, que demandam uma vacinação em massa a nível mundial, a pesquisa poderá prosseguir, numa análise sobre os novos procedimentos adotados em fronteira para controle epidemiológico, e seus impactos nas migrações. Além disso, análises sobre a democracia no Brasil também poderão ser aprofundadas, e o desfecho das ações judiciais contra as portarias (ainda em trâmite, na elaboração desta pesquisa) também poderão indicar as mudanças legais no tema, ou a consolidação dos princípios existentes.

Se os apontamentos de Arendt e Weber foram certeiros quanto ao autoritarismo do século passado, podem lastrear os caminhos a serem tomados agora. Porém vivemos uma realidade que provavelmente era inimaginável até mesmo para os cientistas em questão, o que demanda ações muito mais criteriosas sobre o Estado e a democracia, e as relações com o acolhimento de imigrantes pelo Estado Nacional.

O pânico no enfrentamento da "crise migratória", mencionado por Bauman em 2016, é uma arma política junto ao discurso de "securitização" da sociedade. Esses problemas são complexos e controversos: "neles, o imperativo categórico da moral entra em confronto direto com o medo do 'grande desconhecido' simbolizado pelas massas de estranhos à nossa porta" (Bauman, 2017:104). Pelo contexto que se tem desvelado no Brasil, o único medo justificado é o do crescimento do autoritarismo, que tem não só fechado nossas portas, mas atacado os fundamentos constitucionais sobre os quais se ergue a nossa democracia. 


\section{Referências}

ABRUCIO, Fernando Luiz; LOUREIRO, Maria Rita (2018), "Burocracia e Ordem Democrática: desafios contemporâneos e experiência brasileira" in R. Pires, G. Lotta, V. E. Oliveira (Orgs), Políticas Públicas e burocracia no Brasil. Brasília, Instituto de Pesquisa Econômica Aplicada (Ipea).

ABRUCIO, Fernando Luiz; PEDROTI, Paula; PÓ, Marcos Vinícius (2010), “A Formação da burocracia brasileira: a trajetória e o significada das reformas administrativas" in M. R. Loureiro, L. F. Abrucio, R. S. Pacheco (Orgs.), Burocracia e política no Brasil: desafios para a ordem democrática no século XXI. Rio de Janeiro, FGV.

ARAÚJO, Ernesto (2018), Twitter: @ernestojaraujo [Consult. 15.02.2021]. Disponível em https://twitter.com/ernestofaraujo/status/1072253305408098304

ARENDT, Hannah (1989), Origens do Totalitarismo. São Paulo, Companhia das Letras.

ARENDT, Hannah (1999), Eichmann em Jerusalém. São Paulo, Companhia das Letras.

BIEBER, Florian (2020), "Global Nationalism in Times of the COVID-19 Pandemic". Nationalilities Papers [Consult. 12-02-2021]. Disponível em https://doi.org/10.1017/nps.2020.35

BRANDÃO, Rodrigo; CAPECCHI, Daniel (2019), “A inconstitucionalidade dos decretos sobre porte de armas de fogo". Revista Consultor Jurídico [Consult. 15-02-2021]. Disponível em https://www.conjur.com.br/2019-jun-19/opiniao-inconstitucionalidade-decretos-porte-armas

BRESSER PEREIRA, Luiz (2007), "Burocracia Pública e Classes Dirigentes no Brasil". Revista de Sociologia e Política, n. 28, p. 9-31 [Consul. 15-02-2021]. Disponível em https://www.scielo.br/j/rsocp/a/pQN8bBHLdspnXdFKGPJGg9p/?format=pdf\&lang=pt

CARDOSO, Franciele Silva (2012), "O direito como sistema: dever de coerência e as antinomias segundo Norberto Bobbio". Revista Da Faculdade De Direito, Universidade De São Paulo, v. 106 [consult. 05-02-2021]. Disponível em https://www.revistas.usp.br/rfdusp/article/view/67959

CASTELFRANCHI, Juri (2008), As serpentes e o bastão: tecnociência, neoliberalismo $e$ inexorabilidade. Tese (doutorado) - Universidade Estadual de Campinas, Instituto de Filosofia e Ciências Humanas, Campinas, SP. 373 p. [Consult. 11-08-2018].

CHAVES, João (2020), "A atuação da Defensoria Pública da União em favor de imigrantes durante a pandemia de covid-19: um relato de campo", in C. Von Zuben et. al (Orgs.), Migrações internacionais e a pandemia de covid-19. Campinas, NEPO/Unicamp e Observatório das Migrações de São Paulo.

CLARO, Carolina de Abreu Batista (2020), "Do estatuto do estrangeiro à lei de migração: avanços e expectativas". Boletim de Economia e Política Internacional - BEPI, n. 26 [Consult. 10-02-2021]. Disponível em http://repositorio.ipea.gov.br/handle/11058/9820

CONJUR (2019), "Ministério da Justiça recua em regra de deportação e publica nova portaria". Revista Consul. Jurídico [Consult. 10-02-2021]. Disponível em https://www.conjur.com.br/2019out-14/governo-recua-regra-deportacao-publica-portaria

DEFENSORIA PÚBLICA-GERAL DA UNIÃO (2019), Nota técnica $n^{o} 6$ - DPGU/SGAI DPGU/GTMR DPGU [Consult. 08-02-2020]. Disponível em https://www.migalhas.com.br/arquivos/2019/7/art20190726-11.pdf 
DINIZ, Iara (2020), “Com Weintraub, Educação andou para trás no país, dizem especialistas”. A Gazeta [Consult. 28-04-2021]. Disponível em https://www.agazeta.com.br/es/politica/comweintraub-educacao-andou-para-tras-no-pais-dizem-especialistas-0620

DI PIETRO, Maria Sylvia Zanella (2014), Direito administrativo, São Paulo, Atlas.

FERNANDES, Durval; FARIA, Andressa Virginia de. (2017), "O visto humanitário como resposta ao pedido de refúgio dos haitianos". Revista Brasileira De Estudos De População, v. 34 [Consult. 1002-2021]. Disponível em https://doi.org/10.20947/S0102-3098a0012

GARCIA, Luiz, Leandro (2019), “O que é o Pacto Global de Migrações da ONU?”. Politize! [Consult: 27-04-2021]. Disponível em https://www.politize.com.br/pacto-global-migracoes/

GARGARELLA, Roberto (2020), "Democracy and Emergency in Latin America”, in M. Maduro e P. Kahn (Eds.), Democracy in Times of Pandemic: Different Futures Imagined. Cambridge, Cambridge University Press.

GARRETT JR, Gilson (2020), "Ponte da Amizade reabre, mas não é todo brasileiro que pode passar". Revista Exame [Consult. 28.02.2021]. Disponível em https://exame.com/brasil/ponte-da-amizadereabre-mas-nao-e-todo-brasileiro-que-pode-passar/

HALLAL, Pedro C. (2021), "SOS Brazil: science under attack". The Lancet, v. 397. [Consult. 28.04.2021]. Disponível em https://doi.org/10.1016/S0140-6736(21)00141-0

JIMÉNEZ, Alfredo Ramos (2014), La construcción del orden democrático: Burocracia, Tecnocracia y meritocracia, Mérida, Centro de Investigaciones de Política Comparada.

LYNCH, Christian (2020) “A utopia reacionária do governo Bolsonaro (2018-2020)". Insigh Inteligência [Consult. 24.03.2021]. Disponível em https://inteligencia.insightnet.com.br/a-utopiareacionaria-do-governo-bolsonaro-2018-2020/

MACHADO, Samuel Henrique; JÚNIOR, Ernesto Shonle (2018), "Burocracia e banalidade do mal: uma articulação entre os pensamentos de Weber e Arendt". Revista Ágora, n. 22, pp. 317-327 [Consult. 09-02-2021]. Disponível em https://periodicos.ufes.br/agora/article/view/13624

MELLO, Celso Antônio B. de (2014), Curso de Direito Administrativo, 32 ed., São Paulo, Malheiros.

NETO, Thiago O.; GARCIA, Tatiana de S. L.; SPINUSSI, Eduardo (2020), "Pandemia de COVID-19, as fronteiras pelo mundo e o transporte aéreo na Itália". Confins, n. 44 [Consult. 09-09-2021]. Disponível em https://doi.org/10.4000/confins.27577

OLIVEIRA, Mariana; VIVAS, Fernanda; D'AGOSTINO, Rosanne (2020), "Bolsonaro é presidente com mais decretos e MPs questionados no STF no primeiro ano de mandato". TV Globo e G1 [Consult. 15-02-2021]. Disponível em https://g1.globo.com/politica/noticia/2020/03/01/bolsonaroe-presidente-com-mais-decretos-e-mps-questionados-no-stf-no-primeiro-ano-de-mandato.ghtml

OLIVEIRA, Sonale Diane Pastro (2012), "A Ditadura Militar e o insulamento burocrático: o SNI, um estudo de caso". Em Tempo de Histórias, n. 20, pp. 31-48. [Consult. 29-04-2021]. Disponível em https://doi.org/10.26512/emtempos.v0i20.19856

OVALE (2020), "Deportação de estrangeiros pela Polícia Federal dispara durante a pandemia". $O$ Vale. [Consult. 10-02-2021]. Disponível em https://www.ovale.com.br/_conteudo/brasil/2020/09/112976-deportacao-de-estrangeiros-pelapolicia-federal-dispara-durante-a-pandemia.html 
PERISSINOTO, Renato (2014), "O conceito de Estado Desenvolvimentista e sua utilidade para os casos brasileiro e argentino". Revista de Sociologia e Política, v. 22, n. 52, pp. 59-75.

POLÍCIA FEDERAL (2020), "Polícia Federal deporta bolivianos que entraram no país de forma irregular". Ministério da Justiça e Segurança Pública. [Consult. 10-02-2021]. Disponível em https://www.gov.br/pf/pt-br/assuntos/noticias/2020/11-noticias-de-novembro-de-2020/policiafederal-deporta-bolivianos-que-entraram-no-pais-de-forma-irregular

PONTES, Felipe (2021), "Juiz federal barra deportação de 55 indígenas Warao venezuelanos". Agência Brasil [Consult. 10-02-2021]. Disponível em https://agenciabrasil.ebc.com.br/justica/noticia/2021-01/juiz-federal-barra-deportacao-de-55-

indigenas-warao-venezuelanos

PORTAL DA CIDADE - FOZ DO IGUAÇU (2020), "Ponte da Amizade segue aberta, apesar de nova portaria que fecha fronteiras". Portal da Cidade - Foz do Iguaçu [Consult. 28-02-2021]. Disponível em https://foz.portaldacidade.com/noticias/regiao/ponte-da-amizade-segue-abertaapesar-de-nova-portaria-que-fecha-fronteiras-3247

PORTAL G1 (2020), "Paulo Guedes compara servidores públicos com parasitas" [Consult. 24.03.2021]. Disponível em g1.globo.com/jornal-nacional/noticia/2020/02/07/paulo-guedescompara-servidores-publicos-com-parasitas.ghtml

RUSEISHVILI, Svetlana (2020), "Quatro lições da pandemia sobre a mobilidade no mundo contemporâneo", in C. Von Zuben et. al (Orgs.), Migrações internacionais e a pandemia de covid19. Campinas, NEPO/Unicamp e Observatório das Migrações de São Paulo.

SEÇÃO JUDICIÁRIA DO ACRE - SJAC (2020), $3^{\mathrm{a}}$ Vara Federal Cível e Criminal da SJAC, Ação Civil Pública, Autos 1004501-35.2020.4.01.3000, Requerente: Defensoria Pública da União e outros; requerido: União Federal, instaurado em 17-08-2020.

SOUZA, Murilo (2021), "Deputados apresentam mais de 30 projetos para anular decretos de Bolsonaro sobre armas". Agência Câmara de Notícias [Consult. 15-02-2021]. Disponível em https://www.camara.leg.br/noticias/728652-deputados-apresentam-mais-de-30-projetos-paraanular-decretos-de-bolsonaro-sobre-armas/

SUPREMO TRIBUNAL FEDERAL - STF (2019), "STF inicia julgamento de ação contra extinção por decreto de conselhos federais da administração pública". STF [Consult. 15-02-2021]. Disponível em http://www.stf.jus.br/portal/cms/verNoticiaDetalhe.asp?idConteudo=413839

WEBER, Max (1999), Economia e sociedade: fundamentos da sociologia compreensiva, tradução de Regis Barbosa e Karen Elsabe Barbosa. Brasília, Editora Universidade de Brasília; São Paulo, Imprensa Oficial do Estado de São Paulo. 


\begin{abstract}
The closure of borders was a measure taken by most countries facing the Covid-19 pandemic, including Brazil, through interministerial ordinances of the federal government. The purpose of this research is to analyze such ordinances, what are the motivations of the Executive Branch, and what these acts mean for democracy and migratory rights. Through the historical-deductive method, using bibliographic research, a theoretical review of bureaucratic and authoritarian government was carried out in Arendt's perspective. Through documentary research (ordinances, Public Civil Action and reports), the legality of the ordinances that they determined to be migratory restrictions was analyzed. It was concluded that the closing of borders, in Brazil, is an authoritarian political project of migratory containment, not of the virus: the interministerial ordinances under analysis represent the use of bureaucracy by the political power to subvert the legal system.
\end{abstract}

Keywords: migrations; pandemic; democracy; bureaucracy.

\title{
Resumen
}

El cierre de fronteras fue una medida adoptada por la mayoría de países frente a la pandemia Covid19, incluido Brasil, mediante ordenanzas interministeriales del gobierno federal. El propósito de esta investigación es analizar tales ordenanzas, cuáles son las motivaciones del Poder Ejecutivo y qué significan estos actos para la democracia y los derechos migratorios. A través del método históricodeductivo, utilizando la investigación bibliográfica, se realizó una revisión teórica sobre el gobierno burocrático y autoritario en la perspectiva de Arendt. A través de la investigación documental (ordenanzas, Acción Civil Pública e informes) se analizó la legalidad de las ordenanzas que determinaban las restricciones migratorias. Se concluyó que el cierre de fronteras, en Brasil, es un proyecto político autoritario de contención migratoria, no del virus: las ordenanzas interministeriales analizadas representan el uso de la burocracia por el poder político para subvertir el sistema legal.

Palabras clave: migraciones; pandemia; democracia; burocracia. 